\title{
Klippel-Trenaunay Syndrome Accompanied by the Findings of Scoliosis and Spinal Nerve Root Compression Due to AVM
}

\author{
Yasemin ÖZKAN ${ }^{1}$, Bekir SANAL ${ }^{2}$ \\ 'Department of Physical Medicine and Rehabilitation, Dumlupınar University Faculty of Medicine, Kütahya, Turkey \\ ${ }^{2}$ Department of Radiology, Dumlupınar University Faculty of Medicine, Kütahya, Turkey
}

\begin{abstract}
Klippel-Trenaunay Syndrome (KTS) is one of the rare congenital hyperplasia syndromes generally involving a single extremity characterized by port-wine-stain-type cutaneous vascular malformations, bone and soft tissue hypertrophy, and varicose veins. It was described by the French doctors Maurice Klippel and Paul Trenaunay for the first time in 1900s. Later, the investigators Parkes and Weber described the accompanying arterial abnormalities, arteriovenous fistula, and arterial aneurysms. The disease affects men and women at an equal rate and is not limited to any racial groups. The purpose of this article is to introduce an extremely rare case of KTS with three hypertrophic extremities, presenting with the findings of spinal nerve root compression due to arteriovenous malformation located in the lumbar spinal canal with a literature review.

Keywords: Klippel-Trenaunay syndrome, spinal nerve root compression, AVM
\end{abstract}

\section{Introduction}

Klippel-Trenaunay, a hyperplasia syndrome, generally involves a single extremity that often occurs during delivery or in early childhood and which is characterized by cutaneous hemangioma, congenital venous abnormalities, and hypertrophy in the skeleton and soft tissue (1-3). In this paper, we reported a case of an extremely rare case with KTS.

Klippel-Trenaunay Syndrome (KTS) is one of the rare congenital hyperplasia syndromes, generally involving a single extremity, characterized by port-wine stain type cutaneous vascular malformations, bone and soft tissue hypertrophy and varicose veins. It was described by the French doctors, Maurice Klippel and Paul Trenaunay, for the first time in 1900s. After- wards, the investigators named Parkes and Weber described the accompanying arterial abnormalities, arteriovenous fistula and arterial aneurysms. The disease affects men and women at an equal rate, and is not limited to any racial groups.

The purpose of this article is to introduce an extremely rare case with KTS with three hypertrophic extremities, presenting with the findings of spinal nerve root compression due to arteriovenous malformation located in the lumbar spinal canal, in company with literature.

\section{Case Report}

An 18-year-old male patient presented to our clinic with complaints of increasing persistent lower back pain and numbness and pain in both legs for 2 weeks.

Address for Correspondence: Yasemin Özkan, MD, Dumlupınar Üniversitesi Tıp Fakültesi, Fiziksel Tıp ve Rehabilitasyon Anabilim Dalı, Kütahya, Türkiye. Phone: +902742236053 E-mail: ftrjo@hotmail.com

Received: December 2013 Accepted: March 2014 
Physical examination demonstrated evident hypertrophy in bilateral lower extremities and upper extremity on the right side. "Port-wine stain" lesions were observed that were disseminated in the bilateral lower extremities and upper extremity on the right side, spreading to the abdominal and dorsal regions (Figure 1).

Furthermore, diffuse varicose veins were observed in bilateral lower extremities that were more evident on the left side (Figure 2).

The skin lesions observed in the physical examination were also present during delivery. Hypertrophy of bilateral lower extremities and right upper extremity was distinguished at the age of 5 and gradually increased until the age of 18 .

The muscle strength of the knee flexion, ankle dorsiflexion, and ankle plantarflexion on the left side were $4 / 5,3 / 5$, and $3 / 5$, respectively, as shown by neurological examination. The Achilles and patella reflexes were hypoactive; hypoesthesia and dysesthesia were detected in the dermatomes of the left L3, L4, L5, S1, and straight leg raise $\left(45^{\circ}\right)$, and Lasegue's tests were found positive.

In the patient with hypertrophy in the right upper extremity and bilateral lower extremities, the circumference of the extremity was measured as $45-47 \mathrm{~cm}$ at the femoral level, $35-37 \mathrm{~cm}$ at calf level, and $25-27 \mathrm{~cm}$ at the malleolus level for the right-left lower extremity. The circumference of the right upper extremity was measured 5-cm wider than that of the left side (Figure 3).

The patient was subjected to lumbar and extremity radiographies, abdominal ultrasonography (US), color Doppler USG of the lower-upper extremities, thoracic and full abdominal computed tomography (CT), and lumbar magnetic resonance imaging (MRI). The radiographs (or the computed tomography topogram images) of the case demonstrated an appearance of scoliosis with left-sided concavity in the dorsal region and an appearance of scoliosis with right-sided concavity in the lumbar region (Figure 4).

No pathological finding was identified in the arterial Doppler US of the upper and lower extremities.

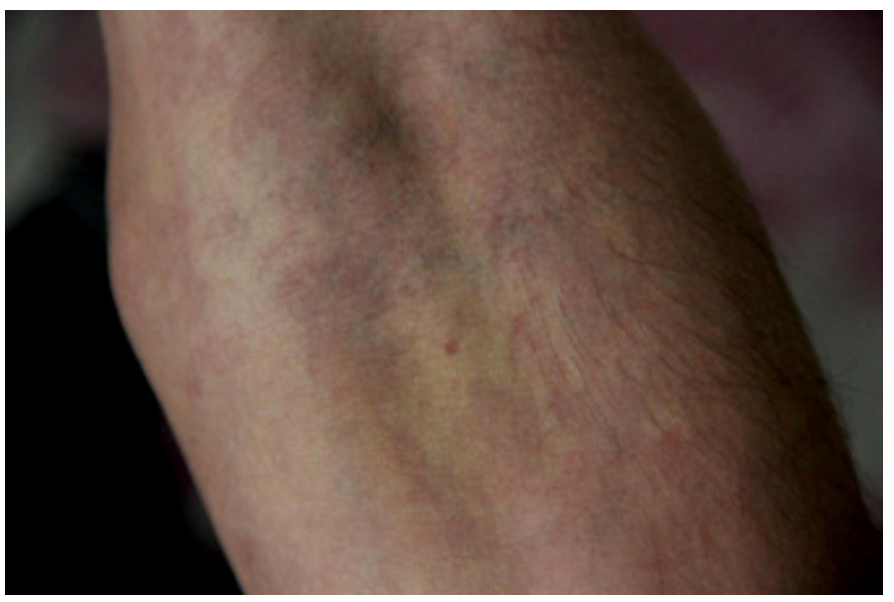

Figure 1. Arm
The superficial venous system in the hypertrophic right arm was wider compared with that of the other arm in the venous Doppler US of the upper extremity. However, no evidence of venous malformation and thrombosis was detected.

The venous Doppler US of the lower extremities demonstrated grade- 2 insufficiency in the superficial venous system; yet no insufficiency of the deep venous system was determined. However, non-thrombosed multiple varicose veins, the greatest

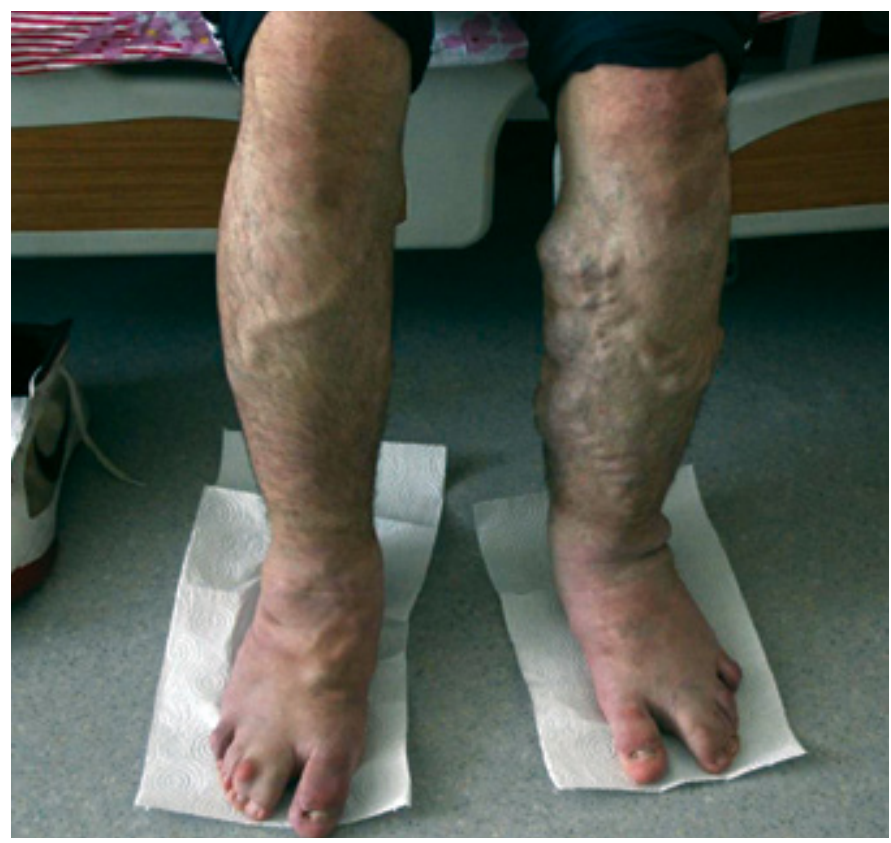

Figure 2. Lower extremities

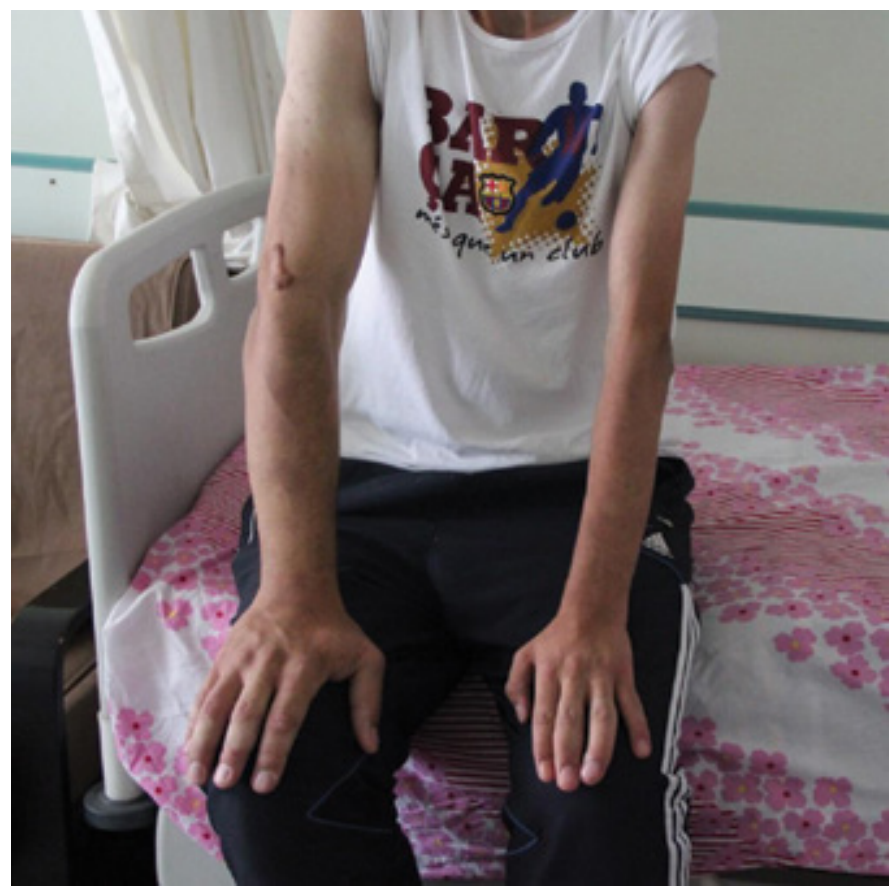

Figure 3. Hypertrophy in the right upper extremity 
of which was measured as $4.5 \mathrm{~cm}$ in diameter, were observed joining in the saphena magna parva.

The size of the liver, spleen, and bilateral kidney was observed at the upper limit as shown in the full abdominal ultrasonography. No other pathological finding was detected.

In the lumbar MRI scan, T1-T2 weighted sequences revealed multiple tortuous hypointense lesions in consecutive order at the right posterolateral epidural space of the spinal canal throughout the L3-L4 vertebrae. The lesion induced compression on the dural sac from the posterior part obliterating the right lateral recess and resulted in compression on the L3, L4 roots by extending towards the neural foramen (Figure 5).

No pathological finding was observed in the thoracic and full abdominal CT scans.

We report a case of PD after we obtained the informed consent of the patient.

\section{Discussion}

Klippel-Trenaunay is one of the hyperplasia syndromes, generally involving a single extremity that often occurs during delivery or in the early childhood and which is characterized by cutaneous hemangioma, congenital venous abnormalities, and hypertrophy in the skeletal and soft tissue (1-3).

It was described by the French doctors Maurice Klippel and Paul Trenaunay for the first time in 1900s (1). Later, the investigators Parkes and Weber described the accompanying arterial abnormalities, arteriovenous fistula, and arterial aneurysms $(4,5)$.

The presence of at least two of the three main clinical pictures is diagnosis for KTS. While these three characteristics involved in the classical triad of KTS exist together only in $63 \%$ of patients, the frequency of capillary malformations, varicosity

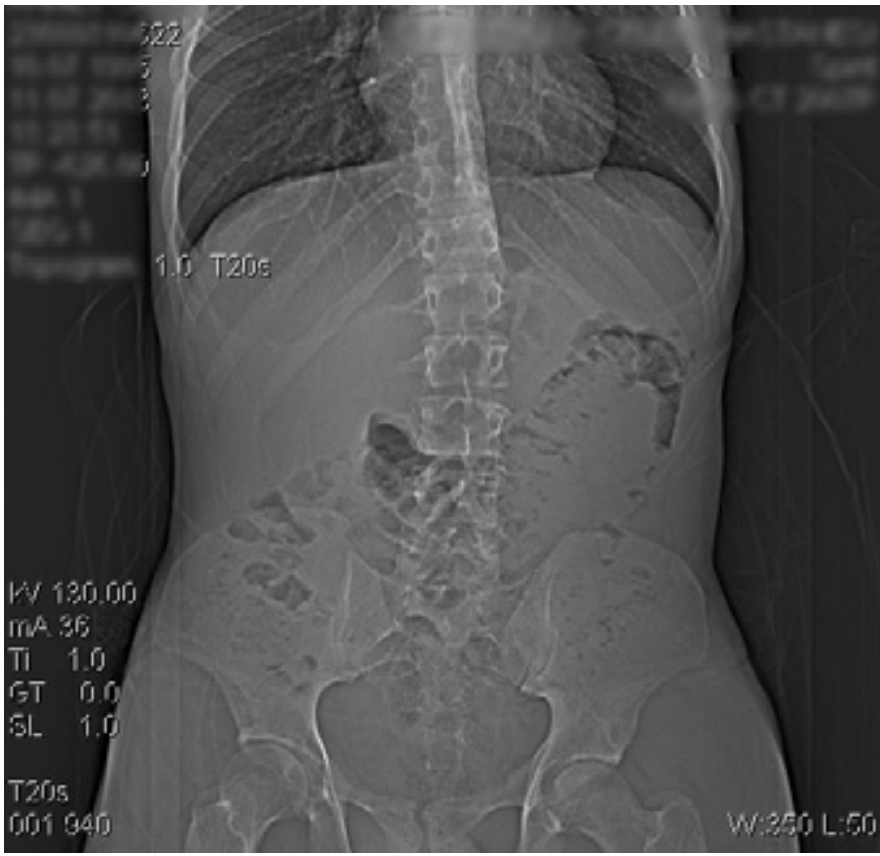

Figure 4. Scoliosis in the AP radiograph (or topogram) and venous malformation, and extremity hypertrophy is $98 \%$, $72 \%$, and $67 \%$, respectively (6). Our case involves three cardinal symptoms falling within the classical triad of the disease.

Although the exact etiology of the disease is unknown, the major possibility is that the abnormalities of the mesodermal tissues responsible for the angiogenesis are liable for the disease during the fetal life. The vascular endothelial growing factors are involved in this complicated process as critical regulators. There is some evidence that it may be associated with a translocation at $(8 ; 14)(q 22.3 ; q 13)$. Some researchers have suggested that VG5Q (Vasculogenesis gene on $5 q$ protein) has an association (7-11).

In addition to visceral hemangioma, a number of cases that have generally been described as non-life threatening KTS affect the organs of the Gl system, including the liver, spleen, bladder, kidney, lungs, and heart. Particularly vascular malformations, involving the vascular system, can be a significant source of morbidity and even mortality in these cases. Resection of the involved intestinal segment is required in patients with KTS and life-threatening hemorrhage. No visceral involvement and hemangioma in visceral organs were observed in our patient (12-15).

According to a study performed at the Mayo Clinic (15), port-wine-stain-type hemangioma, varicose veins or venous malformations, and leg hypertrophy were determined with a rate of $98 \%, 72 \%$, and $67 \%$, respectively, in KTS (15). In our case, three clinical pictures have been concomitantly observed.

Extremity involvement in KTS occurs as unilateral with a rate of $85 \%$; as bilateral with a rate of $12.5 \%$; and as cross-bilateral with a rate of $2.5 \%$, whereas it affects bilateral lower or upper

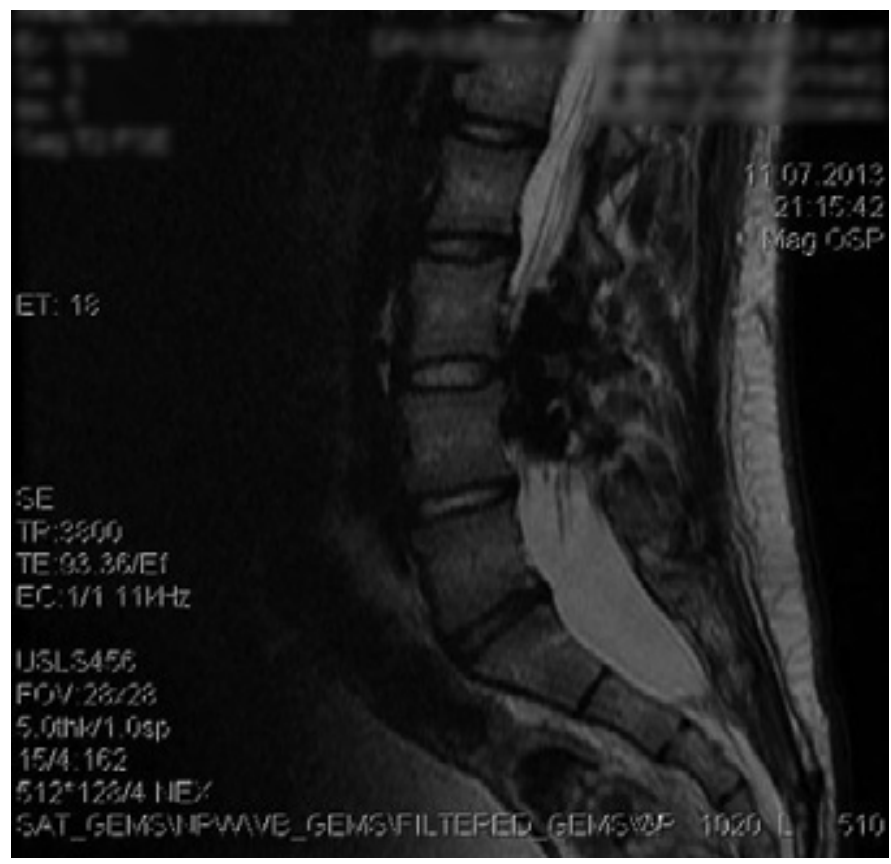

Figure 5. Compression of the dural sac and nerve root and hypointense epidural lesion consistent with venous malformation on the right side of the spinal canal in sagittal T1 and T2 and axial T2 sequences in Lumbar MR scan 
extremities in $10 \%$ of patients $(16,17)$. The involvement of three extremities concomitantly as in our case is a rare type of involvement for KTS.

The characteristic skin lesion is port-wine-stain-type cutaneous hemangioma. The color of the lesion is dark pink. The term "capillary malformation" is used at the present time. This is because actual hemangiomas are tumoral formations with mycotic activity, whereas static endothelium is contained in the capillary malformations in KTS (18). Skin lesions of our patient were birthmarks.

Hemihypertrophy often involves a single extremity. It slowly begins to build up following birth. The main reason is excess of soft tissue and fat. The over development of the bone tissue also contributes to hypertrophy. Venous enlargement is observed from the foot to the calf. In a study performed by Browse et al. (19), hypoplasia/aplasia in the deep venous system was identified with a rate of $18 \%$ in 49 patients with KTS. Redondo et al. (20) reported the same with a rate of $22 \%$. In our case, hypertrophy findings were present in three extremities, and they are considered to contribute particularly to lower extremity pain.

Abnormalities of the superficial veins range from ectasia of small veins, varicosities, and malformation to persistent embryologic veins (15).

It is important to scan the deep venous system prior to vascular intervention. Doppler USG may be used for scanning purposes to determine arteriovenous malformations (AVM) in patients older than 1 year. Magnetic resonance is used to examine the deep pelvic and thoracic regions in cases of a vascular lesion extending throughout the leg. Arteriography is indicated in case of suspected involvement of the brain or spinal cord. Venography is not employed very often. Doppler USG is used for the diagnosis of venous insufficiency. Hemangiomas should be protected against trauma with the arrangements for the risk of bleeding made.

It may progress into lower back/leg pain, weakness, and even cauda equina syndrome in patients with spinal location as in our case. Pressure was observed mostly to be in the right posterolateral area in the MRI images of our patient; however, clinical and neurological findings were determined in the left extremity. This can be explained with the fact that the mass being in vascular origin, dynamic nature of the inner mass fluid, and pressure differences in the mass. The cystic enlargement also observed in MRI images, which extend into the sacral region, can be the cause of left extremity weighted symptoms.

No electromyelography (EMG) was performed because the patient did not provide his consent to EMG testing.

The treatment of KTS is primarily conservative and symptomatic. Varsity socks and pneumatic compression therapy reduce the venous insufficiency. Cellulitis and thrombophlebitis are treated with antibiotics, analgesics, and leg elevation. Aspirin may be used as a prophylactic therapy for thrombophlebitis and prior to surgical intervention and pregnancy. Most centers avoid surgical intervention for venous insufficiency. This is because certain complications, such as infection, lymphatic discharge, and skin detachment, are frequently experienced following surgical treatment. Furthermore, the recurrence following varicose vein surgery was reported as $50 \%$ (18). In selected cases, sclerotherapy or endovenous laser ablation may be employed as an alternative to surgical intervention. Hemangiomas should be protected against trauma before surgical intervention with the arrangements for the risk of bleeding made.

Consequently, we agree that it is important to establish the diagnosis and initiate the appropriate supportive therapy for the disease in the early childhood to inhibit venous insufficiency. As in our case, the treatment that was not initiated at the early stage was unlikely to avoid differences in the diameters and circumferences of the extremities that could be inhibited to an extent, resulting in an early and more complicated exposure of the late-treatment group of patients to the venous insufficiency of the lower extremity. We believe that the early, systematic use of treatment options, which are already limited, may provide the maximum benefit and would highlight the importance of early diagnosis. We suggested pharmacological treatment and bilateral use of compression socks to our patient for the treatment of venous insufficiency.

We used ice pack application and low frequency analgesic flow application to decrease particularly pain and muscle spasm in addition to the medical treatment in acute pain periods of our patient. Surgical intervention should be considered in patients with AVM located in the spinal region with progressed clinical complaints as shown by the multidisciplinary evaluation. We consulted with the neurosurgery clinic for the purpose of surgical evaluation of our patient who had continuing weakness in the lower left extremity; however, pain has been decreased to an extent.

\section{Conclusion}

Our article introduced a KTS case interestingly presenting with an overlapping finding of two pathologies, such as lumbar radiculopathy induced by a component of AVM, and eventually has emphasized on the importance of early and symptomatic treatment in these patients.

Informed Consent: Written informed consent was obtained from patient who participated in this case.

Peer-review: Externally peer-reviewed.

Author Contributions: Two authors contributed equally during the preparation of this manuscript.

Conflict of Interest: No conflict of interest was declared by the authors.

Financial Disclosure: The authors declared that this study has received no financial support.

\section{References}

1. Garzon MC, Huang JT, Enjolras O, Frieden IJ. Vascular malformations. Part II: associatedsyndromes. J Am Acad Dermatol 2007;56:541-64. [CrossRef]

2. Lee A, Driscoll D, Gloviczki P, Clay R, Shaughnessy W, Stans A. Evaluation and management of pain in patients with Klippel- Trenaunay syndrome: a review. Pediatrics 2005; 115:744-9. [CrossRef]

3. Al-Salman MM. Klippel-Trenaunay syndrome: clinicalfeatures, complications, and management. Surg Today 1997;27:735-40. [CrossRef] 
4. Gloviczki P, Driscoll DJ. Klippel-Trenaunay syndrome: current management. Phlebology 2007;22:291-8. [CrossRef]

5. Delis KT, Gloviczki P, Wennberg PW, Rooke TW, Driscoll DJ. Hemodynamic impairment, venousseg mental disease, and clinical severity scoringin limbs with Klippel-Trenaunay syndrome. J Vasc Surg 2007;45:561-7. [CrossRef]

6. Atherton DJ. Naevi and Other Developmental Defects. In: Textbook of Dermatology. Champion RH, Burton JL, Ebling FJG, 5th ed. Oxford, Blackwell Scientific Publications, 1992:445-526.

7. Whelan AJ, Watson MS, Porter FD, Steiner RD. Klippel- TrenaunayWeber syndrome associated with a 5:11 balanced translocation. Am J Med Genet 1995;59:492-4. [CrossRef]

8. Marx MV. SIR 2005 Annual Meeting Film Panel case: Klippel-Trenaunay-Weber syndrome. J Vasc Interv Radiol 2005;16:1173-8. [CrossRef]

9. Oduber CE, Van der Horst CM, Hennekam RC. Klippel-Trenaunay syndrome: diagnostic criteria and hypothesis on etiology. Ann Plast Surg 2008;60:217-23. [CrossRef]

10. Timur AA, Driscoll DJ, Wang Q. Biomedicine and diseases: The Klippel-Trenaunay syndrome, vascular anomalies and vascular morphogenesis. Cell Mol Life Sci 2005;62:143447. [CrossRef]

11. Tian XL, Kadaba R, You SA, Liu M, Timur AA, Yang L, et al. Identification of an angiogenic factor that when mutated causes susceptibility to Klippel-Trenaunay syndrome. Nature 2004;427:640-5. [CrossRef]

12. Wilson CL, Song LM, Chua H, Ferrara M, Devine RM, Dozois RR, et al. Bleeding from cavernous angiomatosis of the rectum in Klippel-
Trenaunay syndrome: report of three cases and literature review. Am J Gastroenterol 2001;96:2783-8. [CrossRef]

13. Young A, Ackroyd J, Baskerville P. Combined vascular malformations. Philadelphia: Saunders; 1988. p.246-74.

14. Gandolfi L, Rossi A, Stasi G, Tonti R. The Klippel-Trenaunay syndrome with colonic hemangioma. Gastrointest Endosc 1987;33:442-5. [CrossRef]

15. Jacob AG, Driscoll D], Shaughnessy W], Stanson AW, Clay RP, Gloviczki P. Klippel-Trenaunay syndrome: spectrum and management. Mayo Clin Proc 1998;73:28-36. [CrossRef]

16. Gloviczki P, Hollier LH, Telander RL, Kaufman B, Bianco AJ, Stickler GB. Surgical implications of Klippel-Trenaunay syndrome. Ann Surg 1983;197:353-62. [CrossRef]

17. Mulliken J, Young A. Combined vascular malformations. In: Mulliken J, editor. Vascular birthmarks: hemangiomas and malformations. Philadelphia: Saunders; 1988. p.159-72.

18. Noel AA, Glovicz ki P, Cherry KJ Jr, Rooke TW, Stanson AW, Driscoll DJ. Surgical treatment of venous malformations in Klippel-Trénaunay syndrome. J Vasc Surg 2000;32:840-7. [CrossRef]

19. Browse NL, Burnand KG, Thomas ML. The Klippel- Trenaunay syndrome. In: Browse NL, Burnand KG, Thomas ML, editors. Diseases of theveins: pathology, diagnosis and treatment. London: Edward Arnold; 1988. p.609-25.

20. Redondo P, Bastarrika G, Aguado L, Martínez-Cuesta A, Sierra A, Cabrera J, et al. Footor hand malformations related to deep venous system anomalies of the lower limb in Klippel-Trenaunay syndrome. J Am Acad Dermatol 2009;61:621-8. [CrossRef] 